\title{
Early-life exposure to severe famine is associated with higher methylation level in the IGF2 gene and higher total cholesterol in late adulthood: the Genomic Research of the Chinese Famine (GRECF) study
}

\author{
Luqi Shen ${ }^{1 \dagger}$, Changwei $\mathrm{Li}^{1 \dagger}$, Zhenghe Wang ${ }^{2}$, Ruiyuan Zhang ${ }^{1}$, Ye Shen ${ }^{1}$, Toni Miles ${ }^{1}$, Jingkai Wei ${ }^{3}$ and
} Zhiyong Zou ${ }^{2 *}$

\begin{abstract}
Objective: To evaluate the association of early-life exposure to the Chinese Great Famine (1959-1961) with DNA methylation in IGF2 and its subsequent influence on blood lipid levels in late adulthood among participants of the Genomic Research of the Chinese Famine (GRECF) study.

Methods: The GRECF study recruited 790 participants born between 1956 and 1964 from 2 neighbor provinces, Anhui and Jiangxi, in China through a multistage, clustered, random sampling. The current study included a random sample of 188 GRECF participants. IGF2 differential methylation region (DMR) is an intragenic DMR located upstream of the imprinted promoters of IGF2 exon 3. DNA methylation were quantified at 8 cytosine-phosphateguanine dinucleotides (CPG) sites at the IGF2 DMR (chr11p15.5) using the Sequenom EpiTYPER method and the MassARRAY system. Multivariate linear regressions were used to evaluate pairwise associations among famine severity, DNA methylation in the IGF2 gene, and lipid levels. We controlled for age and sex in the base model and additionally controlled for education, smoking, and drinking status in the fully adjusted model. Mediation analysis was applied to assess the mediation effect of DNA methylation at the IGF2 gene on the association between earlylife exposure to severe famine and adult lipid levels.

Results: Exposure to severe famine was associated with elevated methylation at CpG1 (chr11: 2126041, build 36) of the IGF2 DMR $(\beta=0.07 ; P=0.0008)$ and total cholesterol $\left(\beta=0.72 ; P=1.09 \times 10^{-7}\right)$. After adjustment for age and sex, each unit increase in methylation of the CpG1 site was associated with 1.09-unit increase in total cholesterol $(P=0.03)$. After further adjustment for all covariates, these associations were still significant ( $P_{\text {famine-CpG } 1}=0.002$, $P_{\text {famine-total cholesterol }}=1.28 \times 10^{-6}$, and $\left.P_{\text {CpG1-total cholesterol }}=0.05\right)$.
\end{abstract}

Conclusion: Increased methylation level in the IGF2 gene was associated with early-life exposure to severe famine, and this change was also positively associated with total cholesterol in late adulthood.

Keywords: DNA methylation, Chinese Famine, HDL-C, LDL-C, Triglycerides, Total cholesterol, Mediation analyses

\footnotetext{
* Correspondence: harveyzou2002@bjmu.edu.cn

+Luqi Shen and Changwei Li contributed equally to this work.

${ }^{2}$ Institute of Child and Adolescent Health, School of Public Health, Peking

University, 38 Xue Yuan Road, Haidian District, Beijing 100191, China

Full list of author information is available at the end of the article
}

(c) The Author(s). 2019 Open Access This article is distributed under the terms of the Creative Commons Attribution 4.0 International License (http://creativecommons.org/licenses/by/4.0/), which permits unrestricted use, distribution, and

reproduction in any medium, provided you give appropriate credit to the original author(s) and the source, provide a link to the Creative Commons license, and indicate if changes were made. The Creative Commons Public Domain Dedication waiver (http://creativecommons.org/publicdomain/zero/1.0/) applies to the data made available in this article, unless otherwise stated. 


\section{Introduction}

Malnutrition during childhood has been associated with a series of health problems indicated by high mortality, morbidity, and mental disability [1-6]. Because of ethical concern, the common practice in epidemiology, such as a malnutrition exposure experiment, has not been and should not be applied to human beings. Alternatively, some natural disasters, such as famine, were widely studied as an ideal (quasi-) natural experiment to investigate the longterm effect of childhood malnutrition. In studies of the Dutch famine in 1944-1945, individuals exposed to famine up to 6 months during gestation was associated with elevated total cholesterol (TC), triglycerides (TG), low-density lipoprotein cholesterol (LDL-C), LDL-C to high-density lipoprotein cholesterol (HDL-C) ratio, and apolipoprotein B, and lower levels of HDL-C and apolipoprotein A [7-9]. Similar studies of the Chinese Great Famine (1959-1961) indicated that early-life exposure to severe famine had excessive risk of dyslipidemia [10]. Furthermore, the Dutch famine study identified that associations of prenatal undernutrition with elevated total cholesterol concentrations and triglycerides only existed among women, but not men [7]. The phenomenon was also found in studies of the Chinese Great Famine [10].

An explanation for these findings is that famine may cause life-long changes in DNA demethylation [11-13] and subsequently increase blood lipid levels in late life [10]. The Dutch famine studies have reported that participants exposed to famine up to 6 months during gestation had different methylation level in late adulthood (>60 years) at the IGF2, INSIGF, IL10, LEP, ABCA1, GNASAS, and $M E G 3$ gene loci, compared to their sex-matched siblings without famine exposure $[12,13]$. In a recent publication, Tobi and colleagues further demonstrated that DNA methylation at 6 genes mediated associations of prenatal famine exposure with triglycerides, an important component of blood lipids [14]. However, the findings are lacking replication in an independent sample.

Compared to the Dutch famine, the Chinese Great Famine lasted much longer and had greater severity. The Chinese Great Famine occurred between 1959 and 1961. According to our previous research, about $11.6 \%$ of the middle-aged and older Chinese adults had family member(s) starve to death during that period [15]. In addition, post-famine food supplies were not fully recovered until 20 years later in the 1980s [16]. Therefore, DNA methylation changes in the above mentioned genes should be more prominent and cause larger effect in lipid profiles among individuals exposed to the Chinese Great Famine. Study of the Chinese Great Famine provides a unique opportunity to replicate findings in the Dutch famine studies and, more importantly, may reveal novel associations between methylation in those genes and lipid profiles.
Therefore, we conducted the first study to explore the associations of early-life exposure to the Chinese Great Famine with blood lipids and to assess the mediation effect of methylation in IGF2 gene, the best-characterized epigenetic loci, on the famine-lipids association in a Chinese population.

\section{Materials and methods \\ Data source and study participants}

The Genomic Research of the Chinese Famine (GRECF) study was designed to evaluate the impact of the Chinese Great Famine on human genome and the subsequent consequences on metabolic disorders. The GRECF study was conducted between July 2015 and January 2016 among residents of Anhui and Jiangxi provinces, China. The 2 provinces were chosen as study sites because of their large difference in famine severities and similarity in geographic location, ethnic composition, lifestyle, and dietary habits. Historically, famine was most intense in Anhui province and moderate in Jiangxi province $[17,18]$. According to our previous research, $35.5 \%$ of the middleaged and older adults in Anhui province reported having immediate family members starve to death during the Chinese Great Famine in 2011 [15]. Jiangxi province neighbors Anhui province, but only $6.8 \%$ of the middleaged and older residents reported death of family members due to the famine [15]. In addition, the economic development, predominantly agricultural during 1960s, in the 2 provinces was also similar. Therefore, it is reasonable to assume that the 2 provinces would have experienced a similar temporal trend regarding population health, if there was no famine.

Participants of the GRECF study were recruited through a multi-stage, clustered, random sampling. Specifically, in the first stage, 1 well-developed region and 1 developing region were randomly selected in each province. In the second stage, 3 counties and 3 villages in each region were randomly selected. Finally, 30-35 subjects born in the 3 years immediately before (1956-1958), during (19591961), or immediately after (1962-1964) the Chinese Great Famine were randomly selected from each county or village based on birthdate obtained from the National Resident Registration System. Overall, a total of 790 participants consented to participate and completed the anthropometric assessments and survey questionnaires.

Due to limited budget, DNA methylation was profiled among a random sample of 188 participants from GRECF participants who experienced famine as infants or fetus and from those who were born after the famine. The sampling process was stratified by regions, birth cohorts, and gender. In each region-birth cohort-gender stratum, one third of participants were randomly selected to have their DNA methylation at the IGF2 gene 
assayed. The current analyses were performed among those 188 participants.

\section{Famine exposure and covariates in the GRECF study}

Food shortages gradually occurred in late 1958 [19]. For the purpose of this study, we select the start date of the Chinese Great Famine as January 1, 1959, and the end date as December 31, 1961. Therefore, early-life famine exposure was categorized into 2 levels: severe and moderate. Specifically, individuals born in Anhui province were categorized as having severe famine exposure, and participants born in Jiangxi province were considered as having moderate famine exposure.

Age was obtained from the National Resident Registration System. Other demographic and health behavioral information, including gender, education levels, smoking, and drinking, were based on self-report. Education levels were categorized into "no more than elementary school," "middle school," "high school," and "some college or above." Smoking status was categorized as "currently smoking" or "currently not smoking." Drinking status was classified as "a current drinker" or "not a current drinker."

\section{DNA methylation in the IGF2 gene and blood lipid measurement}

Blood samples were collected between August 2015 and May 2016, about 5 decades after the famine. A 4-mL tube of fasting blood sample was collected for each participant. A unique barcode was generated for each participant and attached to the blood tubes. After collection, the fresh venous blood samples were transported at $4{ }^{\circ} \mathrm{C}$ temperature to Peking University Health Science Center, where all samples were separated into plasma and buffy coat and stored at $80{ }^{\circ} \mathrm{C}$ for use. Genomic DNA was extracted from peripheral white blood cells using the salting-out method [20]. The EZ 96-methylation kit (Zymo Research) was used to treat DNA with bisulfite. The Sequenom MassARRAY system (Sequenom, San Diego, CA) was used to quantify DNA methylation levels at 8 cytosine-phosphate-guanine dinucleotides (CpG) sites of the IGF2 gene using the manufacturers' protocol on a 384-well plate. Primers of IGF2 gene was designed using the Epidesigner online application (http://epidesigner.com/start3.html). Details of the primers are presented in Additional file 1: Table S3. CpG sites are numbered according to the position of its cytosine in the amplicon counting from p-ter onwards.

DNA methylation of the IGF2 gene was profiled using the EpiTYPER, a mass spectrometry-based bisulfite sequencing method that enables region-specific DNA methylation analysis in a quantitative and high-throughput fashion [21]. The EpiTYPER has high precision and high inter-lab reproducibility and can detect down to $5 \%$ changes in methylation levels. In the measurement of IGF2 DNA methylation, we strictly followed an EpiTYPER protocol designed specifically for the IGF2 gene, which had stringent quality assurance and quality control measures [22]. Specifically, all reaction agents were from the same batch of products, and standard quality control samples and process blank were used throughout the methylation quantification process. More importantly, all samples were assayed in triplicate. If the triplicate methylation measurements had an extreme value equal to or greater than 3 standard deviation (SD), all data for the sample involved were discarded. The mean success rate for the 8 successfully assayed CpG sites was $87.0 \%$. Among the $8 \mathrm{CpG}$ sites, $6 \mathrm{CpG}$ sites were measured individually, and 2 were measured simultaneously because they could not be resolved due to their close proximity. DNA methylation at a CpG site is quantified as a beta value, which is the ratio of methylated signal intensity to the sum of methylated signal intensity, unmethylated signal intensity, and an offset constant.

Blood lipids were assayed from fasting blood samples at the same time as the blood DNA methylation was collected. TC, LDL-C, and HLD-C were assayed using enzymatic colorimetric tests. TG was calculated using the Friedman formula and was logarithmically transformed for analyses.

\section{Statistical analysis}

Means and standard deviations for continuous and frequencies and percentages for categorical characteristics were calculated for the overall participants and by severities of famine. Continuous variables were checked for normality and log-transformed if necessary. Bivariate association analyses were conducted between famine severity and all covariates using chi-square tests for categorical variables and one-way analysis of variance (ANOVA) for continuous variables.

The associations of famine severity with lipids and DNA methylation at the IGF2 gene were assessed by multivariate linear regressions adjusting for age and sex. After Bonferroni correction, significant $\mathrm{CpG}$ sites in the $I G F 2$ gene were further tested for associations with lipid levels in multivariate linear regression models adjusting for age and sex. To test the robustness of the associations, we additionally controlled for education levels, smoking, and drinking status in the fully adjusted models. Finally, we quantified the mediation effect of DNA methylation at the significant CpG site of the IGF2 gene as the proportion of total famine-lipids relationship mediated by DNA methylation at the significant CpG site of the IGF2 gene. The mediation analysis used the classic 2-regression approach described by Baron and Kenny [23]. Sobel's test of significance was performed to determine the extent to which CpG1 site contributed to the total effect on TC [24]. Models were adjusted for 
age, gender, education level, smoking status, and drinking status."

To reduce potential misclassification of famine severities, sensitivity analyses were performed excluding individuals born within 3 years after the famine. All analyses were performed using the SAS software (version 9.4; SAS Institute Inc., Cary, North Carolina). Two-sided $P$ values were provided, and $P<0.05$ was considered significant. A $P$ value of 0.007 was used to determine significant $\mathrm{CpG}$ site (correcting for 7 independent $\mathrm{CpG}$ sites).

\section{Results}

Characteristics of study participants are presented in Table 1. Participants were on average 54.2 years old. Less than half $(48.4 \%)$ of the participants were males. Only $30.9 \%$ of the participants had high school or more education. Prevalence of current smoking was $36.7 \%$, and $40.4 \%$ were current drinkers. Those in severe famine group were on average 0.7 years older than those in moderate famine group. There were no significant differences in gender, education levels, smoking, or drinking status between the 2 groups.

Multiple adjusted associations between exposure to severe famine, DNA methylation, and lipid levels in adulthood were illustrated in Tables 2-4. After controlling for age and gender, individuals with severe famine exposure in early life had significantly higher TC $(\beta=0.72, P=1.09 \times$ $\left.10^{-7}\right)$, LDL-C $\left(\beta=0.55, P=1.03 \times 10^{-5}\right)$, and HDL-C $(\beta=$ $0.10, P=0.04$ ) in late adulthood (Table 2), compared to those with moderate famine exposure in early life. The associations were stronger among females (Table 2); however, gender differences were not statistically significant. The 2 groups had similar levels of $\log$ transformed TG $(\beta=0.12$,
$P=0.12)$ (Table 2). Meanwhile, early-life severe famine exposure was significantly associated with higher DNA methylation level at CpG1 site in the IGF2 gene. When stratified by gender, the DNA methylation level at CpG1 site in the IFG2 gene was most pronounced among female offspring $(\beta=0.10, P=0.004)$ (Table 3$)$. After controlling for age and gender, exposure to severe famine in early life was associated with 7\% $(P=0.0008)$ increase in DNA methylation level at the CpG1 site, compared to those who experienced moderate famine (Table 3). When restricting to participants born during or before the famine, the associations of famine severity with DNA methylation at the CpG1 site and TC were still significant (Additional file 1: Tables S1 and S2). Finally, DNA methylation at the CpG1 site was also positively associated with TC (Table 4). Per unit increase of DNA methylation in the CpG1 site, ageand sex-adjusted TC increased by $1.09 \mathrm{mmol} / \mathrm{L}(P=0.03)$. No gender difference was observed in the association of this CpG site with TC ( $P$ for interaction $=0.70)$. Furthermore, mediation analysis demonstrated that the mediation path through the CpG1 explained 5\% ( $P=0.30)$ of the association between famine severity and TC in adulthood.

\section{Discussion}

To our knowledge, this is the first epigenetic study of early-life exposure to the Chinese Great Famine and blood lipids in later life. Our study supports a finding from studies of the Dutch famine that early life famine exposure is associated with methylation in the IGF2 gene. Furthermore, we provide a novel evidence that methylation in the IGF2 gene was positively associated with TC in late adulthood. The findings not only help to

Table 1 Characteristics of the GRECF study participants by levels of famine severity

\begin{tabular}{|c|c|c|c|c|}
\hline \multirow[t]{2}{*}{ Covariates } & \multirow{2}{*}{$\begin{array}{l}\text { Overall } \\
(n=188)\end{array}$} & \multicolumn{2}{|c|}{ Famine experience level } & \multirow[t]{2}{*}{$P$} \\
\hline & & Moderate $(n=83)$ & Severe $(n=105)$ & \\
\hline Male, N (\%) & $91(48.4)$ & $43(51.8)$ & $48(45.7)$ & 0.41 \\
\hline Age, years, mean (SD) & $54.2(2.3)$ & $53.8(2.4)$ & $54.5(2.2)$ & 0.0001 \\
\hline \multicolumn{5}{|l|}{ Education levels, $N(\%)$} \\
\hline No more than elementary school & $58(30.9)$ & $30(36.1)$ & $28(26.7)$ & \multirow[t]{4}{*}{0.21} \\
\hline Middle school & $72(38.3)$ & $28(33.7)$ & $44(41.9)$ & \\
\hline High school & $49(26.1)$ & $19(22.9)$ & $30(28.6)$ & \\
\hline Some college and above & $9(4.8)$ & $6(7.2)$ & $3(2.9)$ & \\
\hline Current smoker, $N(\%)$ & $66(36.7)$ & $23(30.7)$ & $43(41.0)$ & 0.16 \\
\hline Current drinker, N (\%) & $76(40.4)$ & $29(34.9)$ & $47(44.8)$ & 0.17 \\
\hline LDL, mmol/L, mean (SD) & $2.9(0.8)$ & $2.6(0.6)$ & $3.2(0.9)$ & $7.91 \times 10^{-7}$ \\
\hline $\mathrm{HDL}$, mmol/L, mean (SD) & $1.3(0.3)$ & $1.2(0.3)$ & $1.3(0.4)$ & 0.007 \\
\hline $\log T G$, mean (SD) & $0.4(0.5)$ & $0.4(0.5)$ & $0.5(0.5)$ & 0.08 \\
\hline $\mathrm{TC}, \mathrm{mmol} / \mathrm{L}$, mean (SD) & $4.9(0.9)$ & $4.4(0.7)$ & $5.2(0.9)$ & $1.64 \times 10^{-9}$ \\
\hline
\end{tabular}

$S D$ standard deviation, $L D L-C$ low-density lipoprotein cholesterol, HDL-C high-density lipoprotein cholesterol, logTG logarithmically transformed triglycerides, $T C$ total cholesterol 
Table 2 Association of exposure to severe famine with lipids among GRECF study participants

\begin{tabular}{|c|c|c|c|c|c|c|c|}
\hline & & \multicolumn{2}{|c|}{ Age- and sex-adjusted model* } & \multirow[t]{2}{*}{$P_{\text {interaction }}{ }^{+}$} & \multicolumn{2}{|c|}{ Fully adjusted model** } & \multirow[t]{2}{*}{$P_{\text {interaction }} \S$} \\
\hline & & Beta ( SE) & $P$ & & Beta( SE) & $P$ & \\
\hline \multirow[t]{3}{*}{ HDL-C } & Overall & $0.10(0.05)$ & 0.04 & 0.17 & $0.11(0.05)$ & 0.04 & 0.30 \\
\hline & Male & $0.03(0.07)$ & 0.63 & & $0.04(0.07)$ & 0.56 & \\
\hline & Female & $0.17(0.07)$ & 0.02 & & $0.15(0.08)$ & 0.06 & \\
\hline \multirow[t]{3}{*}{ LDL-C } & Overall & $0.55(0.12)$ & $1.03 \times 10^{-5}$ & 0.55 & $0.52(0.12)$ & $3.71 \times 10^{-5}$ & 0.90 \\
\hline & Male & $0.47(0.17)$ & $6.26 \times 10^{-3}$ & & $0.48(0.17)$ & $5.79 \times 10^{-3}$ & \\
\hline & Female & $0.62(0.17)$ & $5.65 \times 10^{-4}$ & & $0.53(0.18)$ & $4.48 \times 10^{-3}$ & \\
\hline \multirow[t]{3}{*}{$\log T$} & Overall & $0.12(0.08)$ & 0.12 & 0.41 & $0.10(0.08)$ & 0.22 & 0.52 \\
\hline & Male & $0.20(0.12)$ & 0.11 & & $0.16(0.13)$ & 0.23 & \\
\hline & Female & $0.04(0.10)$ & 0.68 & & $0.09(0.11)$ & 0.42 & \\
\hline \multirow[t]{3}{*}{ Total cholesterol } & Overall & $0.72(0.13)$ & $1.09 \times 10^{-7}$ & 0.98 & $0.67(0.13)$ & $1.28 \times 10^{-6}$ & 0.74 \\
\hline & Male & $0.73(0.19)$ & $2.48 \times 10^{-4}$ & & $0.68(0.20)$ & $1.01 \times 10^{-3}$ & \\
\hline & Female & $0.71(0.18)$ & $1.57 \times 10^{-4}$ & & $0.63(0.19)$ & $1.09 \times 10^{-3}$ & \\
\hline
\end{tabular}

LDL-C low-density lipoprotein cholesterol, HDL-C high-density lipoprotein cholesterol, logTG logarithmically transformed triglycerides, SE standard error *Adjusted for age and sex among the overall sample; adjusted for age among male and female, respectively

${ }^{\dagger}$ Assessed by adding an interaction term, gender $\times$ famine severity to the age- and sex-adjusted model among the overall participants

**Adjusted for age, sex, smoking, drinking, and education level among the overall sample

${ }^{\S}$ Assessed by adding an interaction term, gender $\times$ famine severity to the fully adjusted model among the overall participants

understand the function of IGF2 but aid in delineating the mechanisms of cholesterol metabolism.

The identified associations of early-life famine exposure with blood lipids are in line with a previous populationbased study that individuals who experienced severe famine in their early-life had higher LDL-C in later life than those who experienced moderate famine [10]. Our study provided further evidence that early-life severe famine exposure was also positively associated with TC.

The IGF2 gene encodes insulin-like growth factor II and plays a key role in human development and growth. Animal studies revealed that lgf2 knockout mice mimicked nutritional deficiency in utero and resulted in growth restriction and neonatal glycogen stores reduction [25]. The gene is maternally imprinted and paternally expressed [26-28], and methylation changes in the gene persist until at least middle age [29]. Demethylation of the DMR is linked to loss of imprinting $[28,30]$ and subsequently leads to overexpression of IGF2 [31]. The multifaceted effects of $I G F 2$ and methylation plasticity of its DMR have led many, including our group, to study how diverse early-life environmental conditions influence methylation of this region [13, 32] and its subsequent relations to many metabolic disorders [30,31,33]. Prenatal environmental exposures have important role in the DNA methylation level of imprinted genes including the IGF2. Previous studies have demonstrated that prenatal exposure to maternal stress and anxiety was negatively associated with methylation level in the DMR of IGF2 [34, 35]. On contrary, in Mexican-American newborn children, prenatal phthalate and estradiol exposures increased methylation of the IGF2 DMR [36, 37]. Nutrition supply during pregnancy also influences DNA methylation in the IGF2 gene. Prenatal high-fat and high-sugar diet was associated with higher IGF2 methylation [38]. Our study demonstrated that early-life exposure to the Chinese Great Famine up to 3 years was associated with hyper-methylation in the IGF2 among human, which can inhibit the expression of the IGF2 gene [39] and may cause growth restriction. Interestingly, the Dutch famine study showed that prenatal exposure to famine for 6 months was associated with lower methylation in the IGF2 gene [13]. Meanwhile, methylation in the IGF2 gene was not associated with birth weight in the Dutch famine studies [13]. Therefore, we hypothesize that transient exposure to famine may cause hypomethylation of the gene and trigger growth in utero, while long-term extreme famine exposure may cause hypermethylation in the gene and restrict growth in utero. The difference between our study and the Dutch famine studies may also be attributed to several other factors, such as differences in genetic backgrounds, dietary habits, postfamine food supply, and war experience. Besides distinct genetic backgrounds, people in the Netherlands have a diet relatively rich in animal proteins $[40,41]$, while the Chinese diet is mainly composed of carbohydrates [42]. During the Dutch famine, the distribution of energy intake in the percentage of calories from proteins, fat, and carbohydrates was $12 \%, 19 \%$, and $69 \%$, respectively $[40,12]$. The proportion of energy intake in the percentage of calories from proteins, fat, and carbohydrates was 9.5-9.7\%, 5.5-7.6\%, and $82.9-84.8 \%$ in the Chinese Famine [42]. In addition, food supply in China was not fully recovered until 20 years later in 1980s, while food supply was immediately resolved after the Dutch famine. Finally, the Chinese Great Famine 
Table 3 Association of exposure to severe famine with CpG1 site of the IGF2 gene among GRECF study participants

\begin{tabular}{|c|c|c|c|c|c|c|c|}
\hline \multirow{2}{*}{ Methylation } & & \multicolumn{2}{|c|}{ Age- and sex-adjusted model* } & \multirow[t]{2}{*}{$P_{\text {interaction }}{ }^{\dagger}$} & \multicolumn{2}{|c|}{ Fully adjusted model** } & \multirow[t]{2}{*}{$P_{\text {interaction }} \S$} \\
\hline & & Beta( SE) & $P$ & & Beta( SE) & $P$ & \\
\hline \multirow[t]{3}{*}{ Overall } & Overall & $0.005(0.01)$ & 0.70 & 0.89 & $0.004(0.01)$ & 0.75 & 0.91 \\
\hline & Male & $0.005(0.02)$ & 0.78 & & $0.003(0.02)$ & 0.87 & \\
\hline & Female & $0.006(0.02)$ & 0.76 & & $0.003(0.02)$ & 0.88 & \\
\hline \multirow[t]{3}{*}{ CpG1 site } & Overall & $0.07(0.02)$ & 0.0008 & 0.18 & $0.07(0.02)$ & 0.002 & 0.15 \\
\hline & Male & $0.04(0.02)$ & 0.09 & & $0.03(0.03)$ & 0.24 & \\
\hline & Female & $0.10(0.03)$ & 0.004 & & $0.10(0.04)$ & 0.008 & \\
\hline \multirow[t]{3}{*}{ CpG2 site } & Overall & $-0.01(0.02)$ & 0.82 & 0.56 & $-0.01(0.03)$ & 0.78 & 0.73 \\
\hline & Male & $0.005(0.03)$ & 0.88 & & $-0.002(0.04)$ & 0.95 & \\
\hline & Female & $-0.01(0.04)$ & 0.72 & & $-0.008(0.04)$ & 0.84 & \\
\hline \multirow[t]{3}{*}{ CpG3 site } & Overall & $0.02(0.02)$ & 0.42 & 0.08 & $0.02(0.02)$ & 0.41 & 0.07 \\
\hline & Male & $0.05(0.03)$ & 0.04 & & $0.06(0.03)$ & 0.03 & \\
\hline & Female & $-0.02(0.03)$ & 0.54 & & $-0.02(0.03)$ & 0.45 & \\
\hline \multirow[t]{3}{*}{ CpG4 site } & Overall & $-0.02(0.02)$ & 0.27 & 0.71 & $-0.02(0.02)$ & 0.24 & 0.52 \\
\hline & Male & $-0.01(0.02)$ & 0.54 & & $-0.01(0.02)$ & 0.63 & \\
\hline & Female & $-0.03(0.03)$ & 0.36 & & $-0.04(0.03)$ & 0.22 & \\
\hline \multirow[t]{3}{*}{ CpG5 site } & Overall & $0.01(0.01)$ & 0.24 & 0.64 & $0.01(0.01)$ & 0.29 & 0.83 \\
\hline & Male & $0.008(0.01)$ & 0.33 & & $0.005(0.01)$ & 0.53 & \\
\hline & Female & $0.007(0.01)$ & 0.47 & & $0.01(0.01)$ & 0.33 & \\
\hline \multirow[t]{3}{*}{ CpG6 and CpG7 site } & Overall & $-0.02(0.01)$ & 0.13 & 0.24 & $-0.02(0.01)$ & 0.15 & 0.38 \\
\hline & Male & $-0.004(0.02)$ & 0.78 & & $-0.002(0.02)$ & 0.91 & \\
\hline & Female & $-0.04(0.02)$ & 0.11 & & $-0.04(0.02)$ & 0.12 & \\
\hline \multirow[t]{3}{*}{ CpG8 site } & Overall & $-0.02(0.02)$ & 0.44 & 0.56 & $-0.02(0.02)$ & 0.27 & 0.75 \\
\hline & Male & $-0.005(0.02)$ & 0.83 & & $-0.019(0.02)$ & 0.41 & \\
\hline & Female & $-0.03(0.03)$ & 0.43 & & $-0.04(0.03)$ & 0.26 & \\
\hline
\end{tabular}

SE standard error

*Adjusted for age and sex among the overall sample; adjusted for age among male and female, respectively

${ }^{\dagger}$ Assessed by adding an interaction term, gender $\times$ famine severity to the age- and sex-adjusted model among the overall participants

**Adjusted for age, sex, smoking, drinking, and education level among the overall sample

${ }^{\S}$ Assessed by adding an interaction term, gender $\times$ famine severity to the fully adjusted model among the overall participants

occurred in a no-war period; therefore, confounding effect of stress due to war experience in the Dutch famine survivors may also contribute to the difference.

The current study also identified that DNA methylation at the CpG1 site of the IGF2 gene was positively associated with TC in late adulthood. To our knowledge, this is the first study showing association of DNA methylation of the IGF2 with TC. Similar trends were observed for LDL-C and HDL-C. However, due to small sample size and limited power, we could not find significant associations between the CpG1 and the other 2 lipid components. In previous study, DNA methylation in the IGF2 was positively associated with TG, but not TC among 85 children [43]. TG is more likely to be influence by daily diet, suggesting that variations of the TG is even larger, which can further reduce power to detect an association between the CpG1 and TG in this study. Although further studies are needed to validate the finding in an independent Chinese sample, our study together with the Dutch famine studies indicates that the IGF2 gene is important in lipid metabolism in human. The finding is supported by a recent study among mice, which demonstrated that Igf2 knockout mice displayed altered expression levels of genes involved in lipid and fatty acid metabolisms [25]. Early-life nutrition supply, development and growth, and lipids in adulthood warrant further investigation.

Finally, differential methylation at the CpG1 unit of IGF2 contributed to a fairly small proportion (5\%) of the association between famine severity and adult TC levels. Still, a large proportion of famine-TC association remains unexplained. Future genome-wide epigenetic studies are warranted to identify more methylation regions underlying such association.

Our study represents the first epigenetic research on the early-life exposure to the Chinese Great Famine and lipid levels in late adulthood. The current study has several 
Table 4 Association between CpG1 site of the IGF2 gene and lipids among GRECF study participants

\begin{tabular}{|c|c|c|c|c|c|c|c|}
\hline & & \multicolumn{2}{|c|}{ Age- and sex-adjusted model* } & \multirow[t]{2}{*}{$P_{\text {interaction }}{ }^{\dagger}$} & \multicolumn{2}{|c|}{ Fully adjusted model ${ }^{* *}$} & \multirow[t]{2}{*}{$P_{\text {interaction }}{ }^{\S}$} \\
\hline & & Beta( SE) & $P$ & & Beta (SE) & $P$ & \\
\hline \multirow[t]{3}{*}{ LDL-C } & Overall & $0.70(0.44)$ & 0.12 & 0.50 & $0.63(0.44)$ & 0.15 & 0.64 \\
\hline & Male & $0.24(0.79)$ & 0.76 & & $0.22(0.76)$ & 0.77 & \\
\hline & Female & $0.89(0.55)$ & 0.11 & & $0.71(0.55)$ & 0.20 & \\
\hline \multirow[t]{3}{*}{$\mathrm{HDL}-\mathrm{C}$} & Overall & $0.20(0.18)$ & 0.27 & 0.87 & $0.17(0.18)$ & 0.35 & 0.97 \\
\hline & Male & $0.16(0.31)$ & 0.60 & & $0.17(0.33)$ & 0.60 & \\
\hline & Female & $0.22(0.23)$ & 0.34 & & $0.11(0.23)$ & 0.64 & \\
\hline \multirow[t]{3}{*}{$\log T$} & Overall & $0.18(0.28)$ & 0.52 & 0.46 & $0.14(0.29)$ & 0.63 & 0.38 \\
\hline & Male & $-0.12(0.56)$ & 0.83 & & $-0.21(0.56)$ & 0.71 & \\
\hline & Female & $0.31(0.30)$ & 0.31 & & $0.39(0.31)$ & 0.22 & \\
\hline \multirow[t]{3}{*}{ Total cholesterol } & Overall & $1.09(0.49)$ & 0.03 & 0.70 & $0.94(0.48)$ & 0.05 & 0.79 \\
\hline & Male & $0.84(0.91)$ & 0.36 & & $0.66(0.89)$ & 0.46 & \\
\hline & Female & $1.20(0.57)$ & 0.04 & & $1.00(0.58)$ & 0.09 & \\
\hline
\end{tabular}

LDL-C low-density lipoprotein cholesterol, HDL-C high-density lipoprotein cholesterol, logTG logarithmically transformed triglycerides, SE standard error *Adjusted for age and sex among the overall sample; when stratified by gender, age was adjusted among male and female, respectively

${ }^{\dagger}$ Assessed by adding an interaction term, gender $\times$ CpG1 to the age- and sex-adjusted model among the overall participants

**Adjusted for age, sex, smoking, drinking, and education level among the overall sample; when stratified by gender, age, smoking, drinking, and education level were adjusted among male and female, respectively

${ }^{\S}$ Assessed by adding an interaction term, gender $\times$ CpG1 to the fully adjusted model among the overall participants

advantages. First, the timing (occurred 59 years ago), length (lasted for 3 years), and scale (all of mainland China) of the Chinese Great Famine provided a rare opportunity to study the impact of long-term extreme nutrition deprivation during early life on lipid levels in late adulthood. Although a humanitarian disaster in China, famine mimicked a natural experiment of nutrition deprivation and provided an unparalleled opportunity to study changes in DNA methylation due to environmental influence (famine). Second, the Chinese Great Famine happened in a no-war period and a strictly governed society where migration was prohibited. Consequently, it is exempted from some potentially confounding factors, such as psychological stress associated with war and violence experience. Third, most previously studied famine happened in wealthy societies, in which residents suffered from temporary starvation and then recovered with abundant food supplies right after the famine. In contrast, even after the 1959-1961 famine, food supply was limited (although improved to extent degree) for couple decades in China until the market economy reform in 1980s. Therefore, epigenetic changes due to extreme malnutrition during early-life stage can be more likely maintained till later life. As we expected, the Chinese Great Famine was associated with greater changes (7\%) in DNA methylation at the IGF2 CpG1 site in this study compared with that $(3.4 \%)$ in the Dutch famine study. Additionally, we were able to identify associations of early-life exposure to the Chinese Great Famine with LDL and TC not only among women but also man and overall participants, which were missed in the Dutch famine [7, 12]. Several limitations should be mentioned. First, DNA methylation data was measured from peripheral whole blood, which might be not the most relevant tissues to study for lipids, and the cellular heterogeneity of whole blood may contribute as a potential noise. However, previous DNA methylation data from multiple tissues from the same individual showed DNA methylation patterns of the CpG units in whole blood were similar to various fat deposits $[44,45]$. Second, the statistically significant mediation observed in the current study did not clarify the mechanism, but it does provide possible pathways to explore in future. Third, blood lipids and DNA methylation of the IGF2 gene were measured at the same time. The temporal sequence of methylation and lipid changes is unclear. However, DNA methylation of the IGF2 gene is stable and largely driven by genetic factors rather than age-related environmental or stochastic factors $[29,46]$. The IGF2 per se is involved in lipid metabolism. Animal studies identified that disruption of the $\operatorname{Igf2}$ gene alters hepatic lipid homeostasis and gene expression in mice [25]. Negative feedback loop regulation of lipids on IGF2 expression has not been reported. Therefore, it is likely that methylation changes in IGF2 gene results in lipids change. Still, the probability that DNA methylation of the IGF2 gene is partially due to high cholesterol cannot be fully ruled out. Future longitudinal analyses are warranted to delineate the temporal relationship. Forth, cell-type heterogeneity was not corrected in the current study. Compositions of white blood cells change with aging, and cell-type-specific methylation patterns may cause false positive findings. However, Talens and colleagues demonstrated that variations in IGF2 DNA 
methylation were not associated with cell-types in whole blood samples [47]. Furthermore, methylation in the IGF2 gene measured from whole blood samples is highly correlated with that in other tissues [47]. Therefore, we did not correct for cell-type heterogeneity in the current study. Previous study showed that a 10 -year older age was generally associated with a $3.6 \%$ lower methylation [13]. In our study, participants who were exposed to severe famine was 0.7 years older and had higher DNA methylation level, indicating that, if cell-type heterogeneity contributes to IGF2 methylation variation, we may slightly underestimate the methylation level in the exposed group. There should be a larger difference between the exposed group and the reference group if age was perfectly balanced. This also indicates that our finding is robust. Finally, compared to the huge body of Chinese adults who experienced the Chinese Great Famine, our sample size is very small; therefore, sample variation should be large, and this may limit the generalizability of our study findings. Future Chinese Great Famine studies with larger sample sizes are warranted.

\section{Conclusion}

In the present study, we found that increased methylation level in the IGF2 gene may be a consequence of early-life exposure to severe famine during the Chinese Great Famine and this change was also positively associated with TC in late adulthood.

\section{Additional file}

Additional file 1: Supplementary tables. This file contains

supplementary Tables S1-S3. (DOCX $18 \mathrm{~kb}$ )

\section{Abbreviations}

ANOVA: One-way analysis of variance; CpG: Cytosine-phosphate-guanine dinucleotides; GRECF: Genomic Research of the Chinese Famine; HDLC: High-density lipoprotein cholesterol; LDL-C: Low-density lipoprotein cholesterol; TC: Total cholesterol; TG: Triglycerides

\section{Acknowledgements}

Not applicable.

\section{Funding}

The GRECF study was funded by the National Science Foundation of China (NSFC 81402692) and China Scholarship Council (201806015008).

\section{Availability of data and materials}

The datasets generated and/or analyzed during the current study are not publicly available due to the requirement of the Institute Review Board at the Peking University Health Science Center but are available from the corresponding author on reasonable request.

\section{Authors' contributions}

$C L$ and $Z Z$ are responsible for the conceptualization of the study. $L S, Z W, R Z$, and YS contributed to the formal analysis. $C L, T M$, and $Z Z$ supervised the study. $L S$ and $C L$ wrote the original draft of the manuscript. $C L, L S$, and $Z Z$ wrote, reviewed, and edited the manuscript. All authors read and approved the final manuscript.
Ethics approval and consent to participate

The GRECF study was approved by the Institute Review Board at the Peking University Health Science Center.

\section{Consent for publication}

All participants have signed consent forms.

\section{Competing interests}

The authors declare that they have no competing interests.

\section{Publisher's Note}

Springer Nature remains neutral with regard to jurisdictional claims in published maps and institutional affiliations.

\section{Author details}

${ }^{1}$ Department of Epidemiology and Biostatistics, College of Public Health, University of Georgia, Health Sciences Campus, 101 Buck Road, Athens, GA 30602, USA. ${ }^{2}$ Institute of Child and Adolescent Health, School of Public Health, Peking University, 38 Xue Yuan Road, Haidian District, Beijing 100191, China. ${ }^{3}$ Department of Epidemiology, School of Global Public Health, University of North Carolina at Chapel Hill, 135 Dauer Drive, Chapel Hill, NC 27599, USA.

Received: 5 February 2019 Accepted: 29 April 2019

Published online: 10 June 2019

References

1. Bengtsson T, Lindstrom M. Childhood misery and disease in later life: the effects on mortality in old age of hazards experienced in early life, southern Sweden, 1760-1894. Popul Stud (Camb). 2000;54(3):263-77. https://doi.org/ $10.1080 / 713779096$

2. Blackwell DL, Hayward MD, Crimmins EM. Does childhood health affect chronic morbidity in later life? Soc Sci Med. 2001:52(8):1269-84.

3. Kauhanen L, Lakka HM, Lynch JW, et al. Social disadvantages in childhood and risk of all-cause death and cardiovascular disease in later life: a comparison of historical and retrospective childhood information. Int J Epidemiol. 2006:35(4):962-8. https://doi.org/10.1093/ije/dyl046 [published Online First: 2006/03/23]

4. Kuh D, Ben-Shlomo Y, Lynch J, et al. Life course epidemiology. J Epidemiol Community Health. 2003;57(10):778-83.

5. Osler M, Andersen AM, Batty GD, et al. Relation between early life socioeconomic position and all cause mortality in two generations. A longitudinal study of Danish men born in 1953 and their parents. J Epidemiol Community Health. 2005;59(1):38-41. https://doi.org/10.1136/jech. 2004.020990.

6. Wamala SP, Lynch J, Kaplan GA. Women's exposure to early and later life socioeconomic disadvantage and coronary heart disease risk: the Stockholm Female Coronary Risk Study. Int J Epidemiol. 2001:30(2):275-84.

7. Lumey LH, Stein AD, Kahn HS, et al. Lipid profiles in middle-aged men and women after famine exposure during gestation: the Dutch Hunger Winter Families Study. Am J Clin Nutr. 2009;89(6):1737-43. https://doi.org/10.3945/ ajcn.2008.27038 [published Online First: 2009/04/22].

8. Roseboom T, de Rooij S, Painter R. The Dutch famine and its long-term consequences for adult health. Early Hum Dev. 2006;82(8):485-91. https://doi. org/10.1016/j.earlhumdev.2006.07.001 [published Online First: 2006/07/28].

9. Roseboom TJ, van der Meulen JH, Osmond C, et al. Plasma lipid profiles in adults after prenatal exposure to the Dutch famine. Am J Clin Nutr. 2000; 72(5):1101-6. https://doi.org/10.1093/ajcn/72.5.1101.

10. Wang Z, Li C, Yang Z, et al. Fetal and infant exposure to severe Chinese famine increases the risk of adult dyslipidemia: Results from the China health and retirement longitudinal study. BMC Public Health. 2017;17(1):488. https://doi.org/10.1186/s12889-017-4421-6 [published Online First: 2017/06/14]

11. Tobi EW, Goeman JJ, Monajemi R, et al. DNA methylation signatures link prenatal famine exposure to growth and metabolism. Nat Commun. 2014:5: 5592. https://doi.org/10.1038/ncomms6592.

12. Tobi EW, Lumey LH, Talens RP, et al. DNA methylation differences after exposure to prenatal famine are common and timing- and sex-specific. Hum Mol Genet. 2009:18(21):4046-53. https://doi.org/10.1093/hmg/ddp353 [published Online First: 2009/08/04].

13. Heijmans BT, Tobi EW Stein AD et al. Persistent epigenetic differences associated with prenatal exposure to famine in humans. Proc Natl Acad Sci 
U S A. 2008;105(44):17046-9. https://doi.org/10.1073/pnas.0806560105 [published Online First: 2008/10/27]

14. Tobi EW, Slieker RC, Luijk R, et al. DNA methylation as a mediator of the association between prenatal adversity and risk factors for metabolic disease in adulthood. Sci Adv. 2018;4(1):eaao4364. https:/doi.org/10.1126/ sciadv.aao4364 [published Online First: 2018/02/06].

15. Li C, Miles T, Shen L, et al. Early-life exposure to severe famine and subsequent risk of depressive symptoms in late adulthood: the China Health and Retirement Longitudinal Study. Br J Psychiatry. 2018.

16. Riskin C. Seven question about the Chinese famine of 1959-1961. China Economic Review. 1998;9(2):111-24. https://doi.org/10.1016/S1043951X(99)80009-1 Elsevier

17. Huang C, Phillips MR, Zhang Y, et al. Malnutrition in early life and adult mental health: evidence from a natural experiment. Soc Sci Med. 2013;97: 259-66. https://doi.org/10.1016/j.socscimed.2012.09.051 [published Online First: 2012/12/20].

18. Huang C, Li Z, Wang M, et al. Early life exposure to the 1959-1961 Chinese famine has long-term health consequences. J Nutr. 2010;140(10):1874-8. https://doi.org/10.3945/jn.110.121293.

19. Smil V. China's great famine: 40 years later. BMJ. 1999;319(7225):1619-21.

20. Chacon-Cortes D, Haupt LM, Lea RA, et al. Comparison of genomic DNA extraction techniques from whole blood samples: a time, cost and quality evaluation study. Mol Biol Rep. 2012;39(5):5961-6. https://doi.org/10.1007/ s11033-011-1408-8 [published Online First: 2012/01/10].

21. Suchiman HE, Slieker RC, Kremer D, et al. Design, measurement and processing of region-specific DNA methylation assays: the mass spectrometry-based method EpiTYPER. Front Genet. 2015;6:287. https://doi. org/10.3389/fgene.2015.00287 [published Online First: 2015/09/17].

22. SEQUENOM. Standard EpiPanel, 2007.

23. Baron RM, Kenny DA. The moderator-mediator variable distinction in social psychological research: conceptual, strategic, and statistical considerations. J Pers Soc Psychol. 1986;51(6):1173-82.

24. Me S. Asymptotic confidence intervals for indirect effects in structural equations models. San Francisco: Jossey-Bass: Sociological methodology; 1982.

25. Lopez MF, Zheng L, Miao J, et al. Disruption of the Igf2 gene alters hepatic lipid homeostasis and gene expression in the newborn mouse. Am J Physiol Endocrinol Metab. 2018. https://doi.org/10.1152/ajpendo.00048.2018 [published Online First: 2018/07/17].

26. Smith FM, Garfield AS, Ward A. Regulation of growth and metabolism by imprinted genes. Cytogenet Genome Res. 2006;113(1-4):279-91. https://doi. org/10.1159/000090843.

27. Sullivan MJ, Taniguchi T, Jhee A, et al. Relaxation of IGF2 imprinting in Wilms tumours associated with specific changes in IGF2 methylation. Oncogene. 1999;18(52):7527-34. https://doi.org/10.1038/sj.onc.1203096.

28. Monk D, Sanches R, Arnaud P, et al. Imprinting of IGF2 PO transcript and novel alternatively spliced INS-IGF2 isoforms show differences between mouse and human. Hum Mol Genet. 2006;15(8):1259-69. https://doi.org/10. 1093/hmg/ddl041 [published Online First: 2006/03/10].

29. Heijmans BT, Kremer D, Tobi EW, et al. Heritable rather than age-related environmental and stochastic factors dominate variation in DNA methylation of the human IGF2/H19 locus. Hum Mol Genet. 2007;16(5):547-54. https:/doi.org/10.1093/hmg/ddm010 [published Online First: 2007/03/05].

30. Cui $\mathrm{H}$, Onyango P, Brandenburg $\mathrm{S}$, et al. Loss of imprinting in colorectal cancer linked to hypomethylation of H19 and IGF2. Cancer Res. 2002;62(22): 6442-6.

31. Cui H, Cruz-Correa M, Giardiello FM, et al. Loss of IGF2 imprinting: a potential marker of colorectal cancer risk. Science. 2003;299(5613):1753-5. https://doi.org/10.1126/science.1080902.

32. Hoyo C, Murtha AP, Schildkraut JM, et al. Methylation variation at IGF2 differentially methylated regions and maternal folic acid use before and during pregnancy. Epigenetics. 2011;6(7):928-36 [published Online First: 2011/07/01]

33. Tobi EW, Heijmans BT, Kremer D, et al. DNA methylation of IGF2, GNASAS, INSIGF and LEP and being born small for gestational age. Epigenetics. 2011; 6(2):171-6 [published Online First: 2011/02/01].

34. Vangeel EB, Izzi $B$, Hompes $T$, et al. DNA methylation in imprinted genes IGF2 and GNASXL is associated with prenatal maternal stress. Genes Brain Behav. 2015;14(8):573-82. https://doi.org/10.1111/gbb.12249 [published Online First: 2015/09/23]
35. Mansell T, Novakovic B, Meyer B, et al. The effects of maternal anxiety during pregnancy on IGF2/H19 methylation in cord blood. Transl Psychiatry. 2016;6:e765. https://doi.org/10.1038/tp.2016.32 [published Online First: 2016/ 03/29].

36. Tindula G, Murphy SK, Grenier C, et al. DNA methylation of imprinted genes in Mexican-American newborn children with prenatal phthalate exposure. Epigenomics. 2018;10(7):1011-26. https://doi.org/10.2217/epi-2017-0178 [published Online First: 2018/06/29].

37. Chen XJ, Chen F, Lv PP, et al. Maternal high estradiol exposure alters CDKN1C and IGF2 expression in human placenta. Placenta. 2018;61:72-9. https://doi.org/10.1016/j.placenta.2017.11.009 [published Online First: 2017/ $11 / 14]$

38. Rijlaarsdam J, Cecil CA, Walton E, et al. Prenatal unhealthy diet, insulin-like growth factor 2 gene (IGF2) methylation, and attention deficit hyperactivity disorder symptoms in youth with early-onset conduct problems. J Child Psychol Psychiatry. 2017;58(1):19-27. https://doi.org/10.1111/jcpp.12589 [published Online First: 2016/08/18].

39. Razin A, Cedar H. DNA methylation and gene expression. Microbiol Rev. 1991;55(3):451-8.

40. Burger GCEDJC, Sandstead HR. Malnutrition and Starvation in Western Netherlands, September 1944-July 1945. The Hague, The Netherlands: General State Printing Office; 1948.

41. Sluijs I, Beulens JW, van der A DL, et al. Dietary intake of total, animal, and vegetable protein and risk of type 2 diabetes in the European Prospective Investigation into Cancer and Nutrition (EPIC)-NL study. Diabetes Care. 2010; 33(1):43-8. https://doi.org/10.2337/dc09-1321 [published Online First: 2009/ 10/13].

42. Du SF, Wang HJ, Zhang B, et al. China in the period of transition from scarcity and extensive undernutrition to emerging nutrition-related noncommunicable diseases, 1949-1992. Obes Rev. 2014;15(Suppl 1):8-15. https://doi.org/10.1111/obr.12122.

43. Deodati A, Inzaghi E, Liguori A, et al. IGF2 methylation is associated with lipid profile in obese children. Horm Res Paediatr. 2013;79(6):361-7. https:// doi.org/10.1159/000351707 [published Online First: 2013/06/15].

44. Relton CL, Gaunt T, McArdle W, et al. Data Resource Profile: Accessible Resource for Integrated Epigenomic Studies (ARIES). Int J Epidemiol. 2015; 44(4):1181-90. https://doi.org/10.1093/ije/dyv072 [published Online First: 2015/05/21]

45. Slieker RC, Bos SD, Goeman JJ, et al. Identification and systematic annotation of tissue-specific differentially methylated regions using the Illumina 450k array. Epigenetics Chromatin. 2013;6(1):26. https://doi.org/10. 1186/1756-8935-6-26 [published Online First: 2013/08/08].

46. Cruz-Correa M, Zhao R, Oviedo M, et al. Temporal stability and age-related prevalence of loss of imprinting of the insulin-like growth factor-2 gene. Epigenetics. 2009;4(2):114-8 [published Online First: 2009/02/27].

47. Talens RP, Boomsma DI, Tobi EW, et al. Variation, patterns, and temporal stability of DNA methylation: considerations for epigenetic epidemiology. FASEB J. 2010;24(9):3135-44. https://doi.org/10.1096/fj.09-150490 [published Online First: 2010/04/12]
Ready to submit your research? Choose BMC and benefit from:
- fast, convenient online submission
- thorough peer review by experienced researchers in your field
- rapid publication on acceptance
- support for research data, including large and complex data types
- gold Open Access which fosters wider collaboration and increased citations
- maximum visibility for your research: over $100 \mathrm{M}$ website views per year
At $\mathrm{BMC}$, research is always in progress. 